\title{
Evidence of transient increases of fluid pressure in SAFOD phase III cores
}

\author{
Silvia Mittempergher, ${ }^{1,2}$ Giulio Di Toro, ${ }^{1,3}$ Jean Pierre Gratier, ${ }^{2}$ Jafar Hadizadeh, ${ }^{4}$ \\ Steven A. F. Smith, ${ }^{3}$ and Richard Spiess ${ }^{1}$ \\ Received 11 November 2010; revised 13 December 2010; accepted 27 December 2010; published 1 February 2011.
}

[1] The San Andreas Fault Observatory at Depth (SAFOD) in Parkfield, central California, has been drilled through a fault segment that is actively deforming through creep and microearthquakes. Creeping is accommodated in two fault strands, the Southwest and Central Deforming Zones, embedded within a damaged zone of deformed shale and siltstone. During drilling, no pressurized fluids have been encountered, even though the fault zone acts as a permeability barrier to fluid circulation between the North American and Pacific plates. Microstructural analysis of sheared shales associated with calcite and anhydrite-bearing veins found in SAFOD cores collected at $1.5 \mathrm{~m}$ from the Southwest Deforming Zone, suggests that transient increases of pore fluid pressure have occurred during the fault activity, causing mode I fracturing of the rocks. Such build-ups in fluid pressure may be related to permeability reduction during fault creep and pressure-solution processes, resulting in localized failure of small fault zone patches and providing a potential mechanism for the initiation of some of the microearthquakes registered in the SAFOD site. Citation: Mittempergher, S., G. Di Toro, J. P. Gratier, J. Hadizadeh, S. A. F. Smith, and R. Spiess (2011), Evidence of transient increases of fluid pressure in SAFOD phase III cores, Geophys. Res. Lett., 38, L03301, doi:10.1029/ 2010GL046129.

\section{Introduction}

[2] The NSF EarthScope San Andreas Fault Observatory at Depth (SAFOD) in Parkfield offers the opportunity to correlate physical and chemical processes identified in core samples with high-resolution seismological and geophysical data [Zoback et al., 2010]. The SAFOD is located in the transition zone between the creeping segment of the SAF (to the north), and the southern "locked" segment, which lastly ruptured in the $1857 \mathrm{M}_{\mathrm{w}} 7.8$ Fort Tejon earthquake (Figure 1a). Near Parkfield, the SAF activity includes permanent creep at about $20 \mathrm{~mm} \mathrm{yr}^{-1}$ [Titus et al., 2006], microearthquakes [e.g., Nadeau and Johnson, 1998] and moderate ( M6) earthquakes-that have nucleated at fairly regular intervals between 1857 and 2004 [e.g., Bakun et al., 2005]. The SAFOD main hole crosses the actively deforming SAF at about $2.7 \mathrm{~km}$ of vertical depth, approximately $100 \mathrm{~m}$ above the hypocentral area of a cluster of repeating M2

\footnotetext{
${ }^{1}$ Dipartimento di Geoscienze, Università di Padova, Padua, Italy.

${ }^{2}$ LGIT, Université Joseph Fourier - Grenoble I, Grenoble, France.

${ }^{3}$ Istituto Nazionale di Geofisica e Vulcanologia, Rome, Italy.

${ }^{4}$ Department of Geography and Geosciences, University of Louisville, Louisville, Kentucky, USA.
}

Copyright 2011 by the American Geophysical Union. 0094-8276/11/2010GL046129 earthquakes, which was one of the targets for drilling [Nadeau et al., 2004]. During 2007, about $40 \mathrm{~m}$ of core was extracted parallel to the main hole, including a section that crosses the two actively creeping strands of the fault detected by borehole casing deformation, named Southwest Deforming Zone (SDZ) and Central Deforming Zone (CDZ) [Zoback et al., 2010] (Figures 1a-1c).

[3] Slip in the SAF occurs at much lower shear stress than expected based on laboratory friction of rock forming minerals [Brune et al., 1969], suggesting that it behaves as a weak fault in a strong crust [Rice, 1992]; such a model is confirmed by down hole stress measurements and mechanical modeling [Hickman and Zoback, 2004; Chéry et al., 2004; Boness and Zoback, 2006]. Pressurization of the fault core by pore fluids was one of the explanations suggested for the low strength of the SAF [Rice, 1992]. Since no fluid pressure higher than hydrostatic has been detected during drilling [Zoback et al., 2010], the most convincing mechanisms remain the presence of intrinsically weak material within the actively creeping sections [e.g., Moore and Rymer., 2007] and the effect of stress driven pressure solution creep processes [Gratier et al., 2009]. The study of the source mechanisms of repeating microearthquakes in Parkfield at depth of 2-5 km reveals peak stress drops exceeding 50MPa [Imanishi and Ellsworth, 2006; Dreger et al., 2007], suggesting that relatively strong asperities exist within an otherwise weak fault zone.

[4] We performed microstructural, mineralogical and geochemical analyses on samples collected at $1.5 \mathrm{~m}$ from the south-eastern boundary of the SDZ. The sampled core shows contemporary occurrence of veins and sheared shales (Figure 1d). Here we provide possible evidence of fracture opening in the presence of fluids and discuss mechanisms for permeability reduction and strength recovery after failure. The analytical techniques applied, including X-Ray Powder Diffraction (XRPD), X-Ray Fluorescence (XRF) mapping, Field-Emission Scanning Electron Microscope (FE-SEM), cathodoluminescence (CL) optical microscope and Electron Back Scatter Diffraction (EBSD), are described in the auxiliary material. ${ }^{1}$

\section{The Sample}

[5] The damage zone of the SAF is identified in the borehole as a zone of low seismic velocities (Figure 1c), and is composed of sheared and fractured shales, siltstones and sandstones of the Great Valley Formation [Solum et al., 2006] (Figure 1b). The studied core section includes sheared Fe-rich

\footnotetext{
${ }^{1}$ Auxiliary materials are available in the HTML. doi:10.1029/ 2010GL046129.
} 


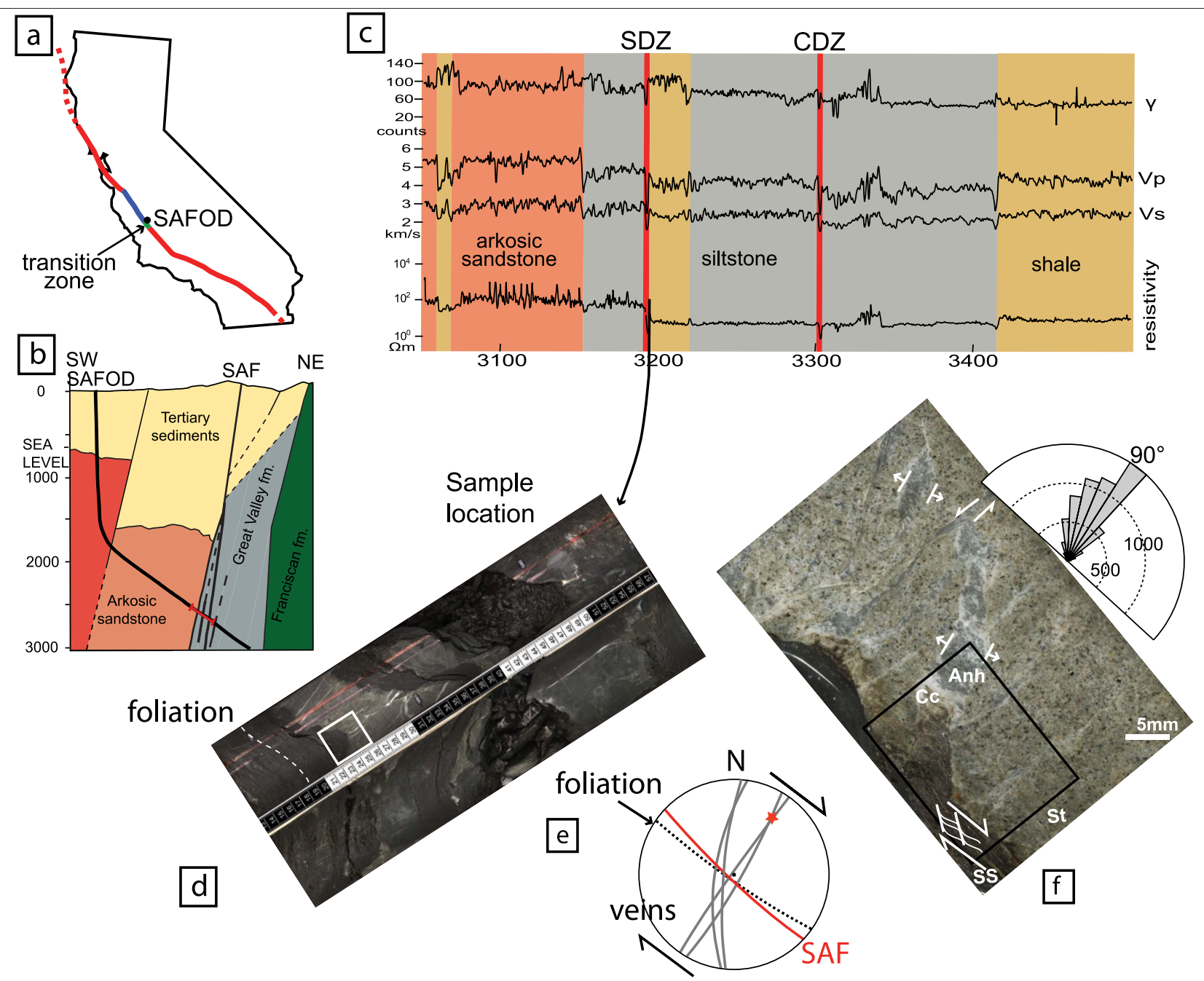

Figure 1. Sample location. (a) Sketch of the SAFOD location in California. The SAF is in red (locked segments), blue (creeping section) and green (transition zone). (b) Schematic geological section of the SAFOD site, parallel to the borehole trajectory (thick black line) [Zoback et al., 2010]. In red, the segment enlarged in Figure 1a. (c) The downhole geophysical logs of the SAFOD main hole, with the location of the sample (black arrow). Highlighted in red, the actively deforming fault strands. (d) The studied core section (image from http://www.earthscope.org/observatories/safod/). (e) Lower hemisphere stereoplot of great circles corresponding to the attitude of the SAF in Parkfield (red, datum from Boness and Zoback [2006]) and the inferred attitude of the foliation planes in the studied core (dotted line) and the vein planes (gray). (f) Polished thin section, reflected light photomosaic (Cc: calcite, Anh: anhydrite, SS: sheared shale, St: sandstone). Inset: rose diagram of the orientation of the anhydrite-calcite veins, referred to the foliation in the gouge; dashed lines contours the number of counted segments (see auxiliary material for details of fracture counting). The black square is the area in Figure 2a.

shales with embedded veined sandstone ribbons (Figure 1d). The phase III cores have been drilled along a trajectory parallel to that of the main hole, and we consider the attitude of the main hole axis as a reference to infer an approximate orientation of the sample. Using the foliation in the shale as reference plane and assuming that its attitude is roughly parallel to the SAF plane (Figures 1d and 1e), the veins are subvertical and make an angle of $40-100^{\circ}$ clockwise with the foliation plane (Figures 1e and 1f).

\section{Observations}

[6] The sandstone in the studied core is medium grained $(<500 \mu \mathrm{m})$, composed of clasts of plagioclase, K-feldspar, quartz, mica and bioclasts and cemented by quartz. Pervasive macroscopic and microscopic veins in the sandstone are sealed by calcite and anhydrite; the veins crosscutting the boundary between sheared shale and sandstone are intruded by the shale (Figures $1 \mathrm{f}$ and $2 \mathrm{a}$ ). The veins oriented at an acute angle to the shale foliation are extensional, while those roughly perpendicular to the shale foliation show extension with a component of sinistral shear (Figure 1f).

[7] The sheared shale is composed of illite and illitesmectite interlayers (altogether 48.9\%), quartz (18.9\%), albite $(14.5 \%), \mathrm{K}$-feldspar (11.2\%) and chlorite (4.9\%), with minor calcite $(1.1 \%)$ and pyrite $(0.5 \%)$ (Rietveld XRPD quantitative analysis). The illite-smectite interlayers contain about $20 \%$ smectite. The sheared shale is foliated along clay-rich 


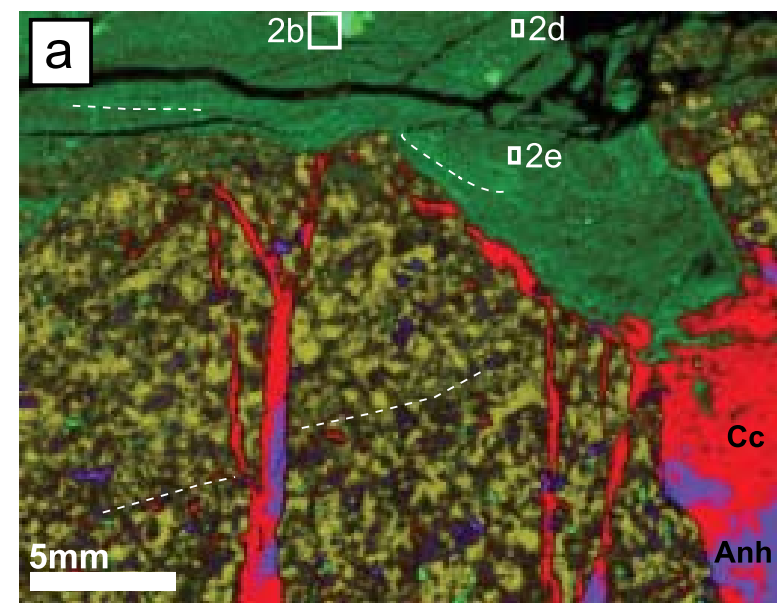

LEGEND

phyllosilicates
(Fe and $\mathrm{Mg}$ )
quartz $(\mathrm{Si})$
plagioclase

K-feldspar ( $\mathrm{K}$ and $\mathrm{Si}$ )

pyrite (S and $\mathrm{Fe})$

calcite (Ca) anhydrite $(\mathrm{S}$ and $\mathrm{Ca})$
$(\mathrm{Si}, \mathrm{Ca}$ and $\mathrm{Na})$
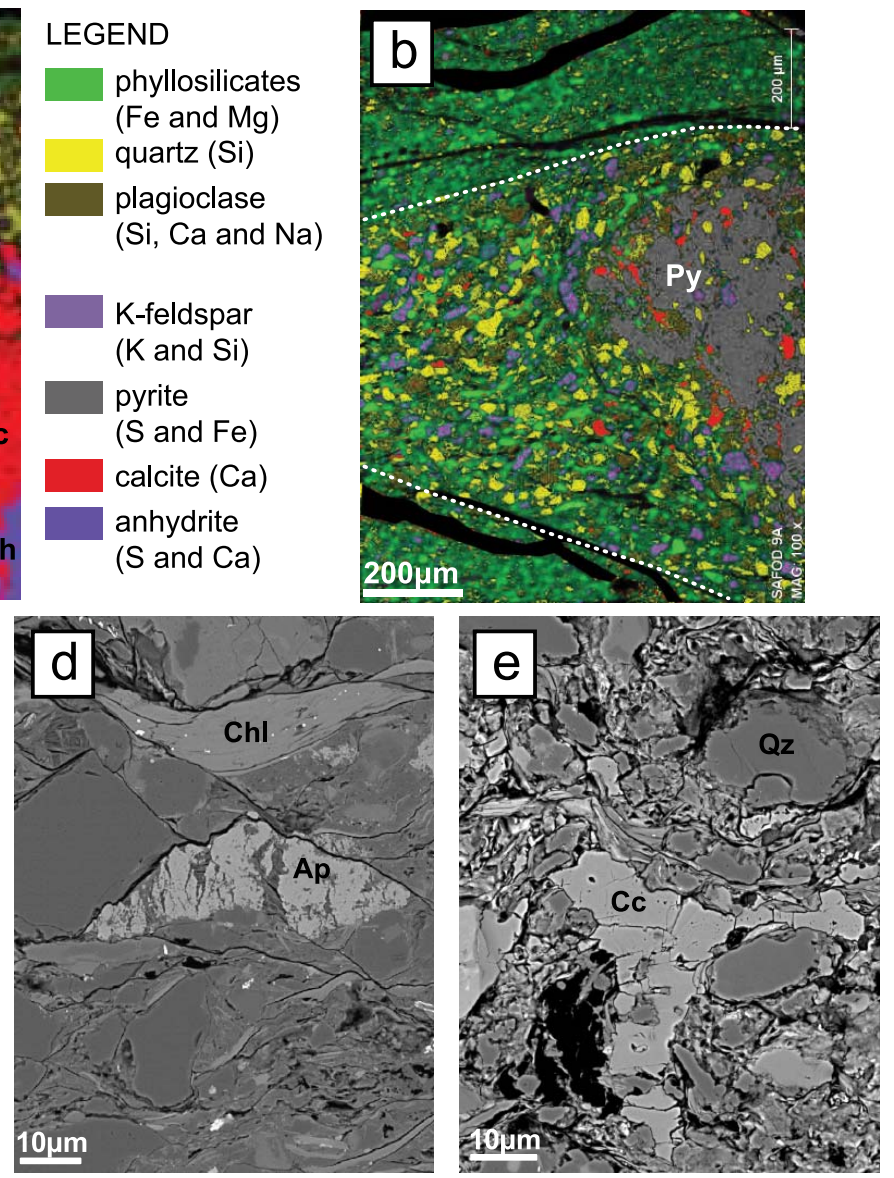

Figure 2. Geochemistry and microstructures. (a) Elemental chemical composition by superimposition of XRF chemical maps. Dashed lines: phyllosilicate-rich dissolution seams. (b) Detail of the elemental composition of a strain shadow around a pyrite clast (Py) within the sheared shale. Outside the strain shadow (dashed white line), there is sharp grainsize reduction, leaching of $\mathrm{Ca}$ and $\mathrm{Si}$, and passive concentration of $\mathrm{Fe}$ and $\mathrm{Mg}$-bearing phyllosilicates (superimposition of SEM-EDS chemical maps). (c) Foliated clay-rich shale with $\mathrm{S}-\mathrm{C}^{\prime}$ foliation (optical micrograph, crossed Nicols). (d) Fractures within an apatite (Ap) clast filled by fibrous Illite-Smectite (I-S) lamellae. The S foliation is defined by a chlorite crystal (FE-SEM BSE image). (e) Blocky calcite filling the pore spaces within the shale particles from the apical part of the vein intruding the sandstone (FE-SEM BSE image).

dissolution seams, bended toward the intrusion in the veins (XRF chemical map, Figure 2a). The material within the foliation planes have smaller grain size and is depleted in $\mathrm{Ca}$, $\mathrm{Na}, \mathrm{K}, \mathrm{Si}$ and enriched in $\mathrm{Fe}$ and $\mathrm{Mg}$ relative to the less deformed shale. This evolution is seen when comparing the foliation with the initial texture preserved within a strain shadow around a pyrite clast (Figure $2 b$ ). Locally the foliation shows an S-C' texture [Passchier and Trouw, 2005] (Figures 2c and 2d). FE-SEM observations show that fibrous, micrometric illite-smectite lamellae have grown in strain shadows around clasts and within intragranular microcracks (Figure 2d). In the apical part of the veins (Figures $2 \mathrm{a}$ and $2 \mathrm{e}$ ) intruded by randomly arranged clays and clasts from the shale layer, the pore spaces are filled by calcite (Figure 2e). The calcite and anhydrite crystals sealing the veins are mostly euhedral, forming a blocky texture [Passchier and Trouw, 2005], and include domains of elongated crystals (Figure 3a). Calcite shows thin and straight twins, a texture typical of deformation at temperatures below $200^{\circ} \mathrm{C}$ [Ferrill et al., 2004]. Under the cathodoluminescence microscope, calcite has either dark or light orange luminescence. In the thick vein in Figure $2 \mathrm{a}$, the calcite crystals close to the vein borders have a dark nucleus and a lighter rim and have a blocky texture. In contrast, the calcite crystals towards the vein centre have light rims alternating with dark rims and crystals are elongated with the long axis perpendicular to the vein walls (stretched-fibrous texture) (Figure 3a). In the latter texture, the associated anhydrite crystals show similar stretched-fibrous crystals associated with microcracks oriented parallel to the long axis of the light and dark luminescence rims in calcite. EBSD analysis on calcite has been performed along the vein borders (blocky calcite, Figure 3b), and towards the vein centre (elongated calcite, Figure 3c). The pole figures in blocky and elongated calcite show preferential distribution maximum density of the ' $c$ ' axes lower than 2.5 times the mean unit density (MUD), indicating a weak crystallographic preferred orientation (CPO). The blocky calcite is characterized by a weak maximum of the 'c' axes in a direction perpendicular to the vein borders. In elongated calcite, the 

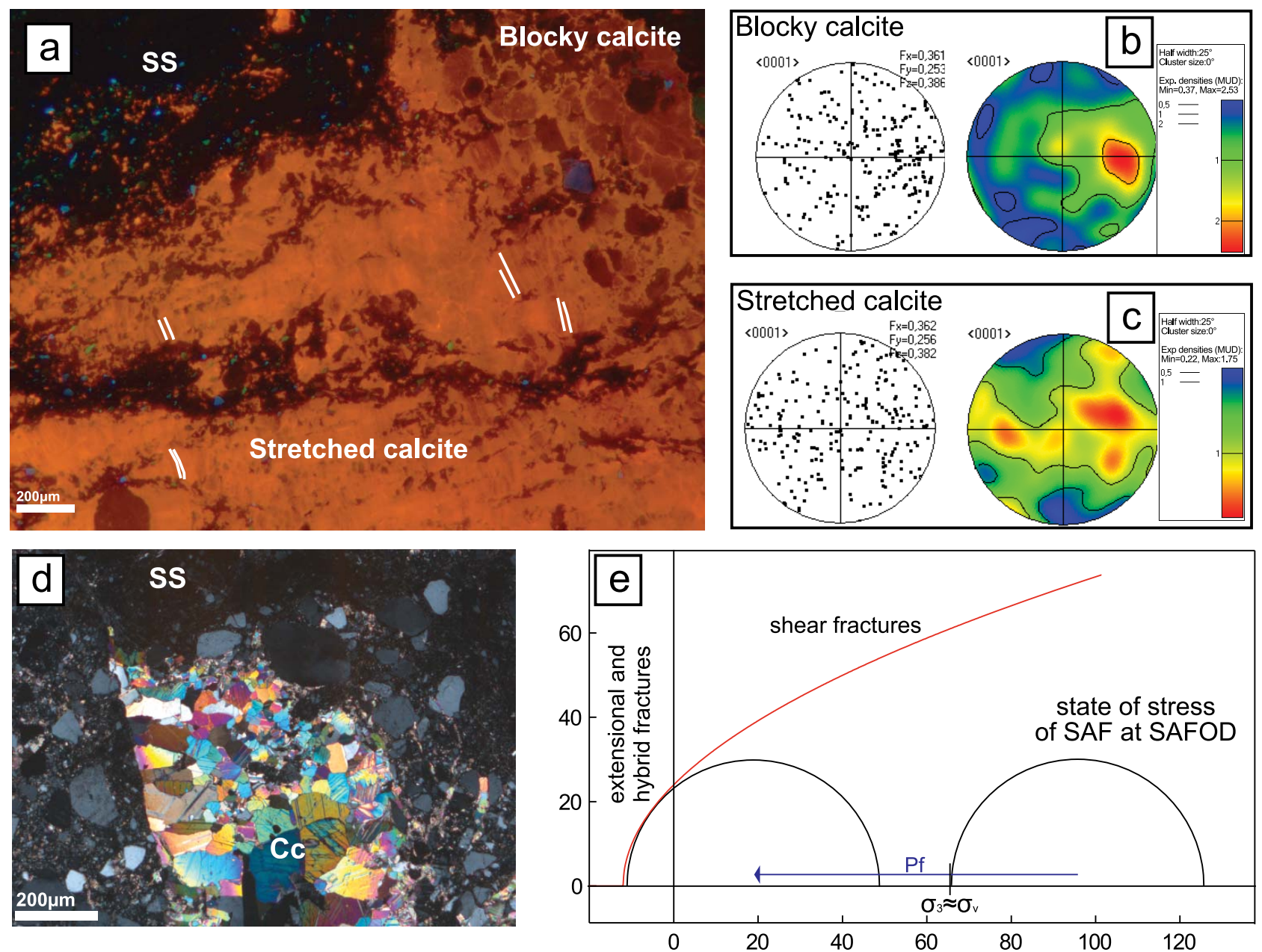

Figure 3. Microstructure of the calcite veins. (a) In blocky crystals close to the vein border, calcite is uniformly dark with a thin light rim; in the stretched calcite toward the vein centre, a fine scale banding of light and dark calcite is visible (CL micrograph). (b, c) EBSD data. C-axes orientation plotted in a lower hemisphere stereogram, as scattered data and contour plots; contours are expressed as multiples of mean unit density (MUD); the horizontal line in the pole figures coincides with the long axis of the CL micrograph. (d) Blocky calcite in the apical part of one of the veins, showing pervasive low temperature twinning. (e) Sketch of the Murrell-Griffith criterion of failure and the state of stress in the vicinity of the SAF [from Hickman and Zoback, 2004]. The conditions for extensional or hybrid fracturing are met when the least principal stress $\sigma_{3}$ is negative, after a negative shift due to pore pressure higher than the lithostatic value.

distribution of 'c' axes shows a minimum parallel to the vein borders, with the 'c' axes plotting within a broad girdle roughly perpendicular to the vein borders.

\section{Discussion and Conclusions}

[8] The creeping deformation within the SAF is localized within the SDZ and the CDZ. The samples we studied are from the deformed sediments at about $1.5 \mathrm{~m}$ from the SDZ margin, and thus the deformation structures we described cannot be rigorously related to the active deformation. The location of the microearthquakes associated to the SAF is even less constrained, since they register static stress drops (up to $120 \mathrm{MPa}$ ) compatible with fracturing in relatively strong rocks [Imanishi and Ellsworth, 2006]. Therefore, we suggest that the microearthquakes might be localized within the damaged zone, or at the boundaries between creeping zones and damage zone. Here we discuss how the defor- mation processes active within the siliciclastic sediments in the damage zone can cause local fluid overpressure and brittle failure.

[9] The development of a foliation in the sheared shale is associated with dissolution of quartz and feldspar clasts and growth of clay lamellae in microcracks. These processes are typical of stress driven pressure solution [Gratier et al., 2009], and might cause permeability reduction due to passive concentration of clay minerals such as illite and illitesmectite, clast size reduction and pore space closure at the micrometric scale. The loss of $\mathrm{Ca}$ and $\mathrm{Na}$ and the passive enrichment in $\mathrm{Fe}$ and $\mathrm{Mg}$ along dissolution planes due to fault-perpendicular compression is a phenomenon documented at all scales in the SAF damage zone [Schleicher et al., 2009; Gratier et al., 2009]. Since dissolution planes are roughly perpendicular to the main compressive stress, they contribute to the development of fault-parallel permeability barriers that may separate compartments with distinct 
fluid composition, as revealed by abrupt changes in real time mud gas analysis observed during drilling into the SAF [Wiersberg and Erzinger, 2008].

[10] Veining and dilational jogs (consistent with dextral sense of shear of the SAF) in other core sections are sealed by calcite and anhydrite, suggesting that mineral precipitation was related to the SAF activity (SAFOD, The core Atlas (version 4), 2010, available at http://www.earthscope. org/es_doc/data/safod/Core\%20Photo\%20Atlas\%20v4.pdf). The blocky texture of calcite and the intimate intergrowth of calcite and anhydrite in the veins indicate that vein opening was faster than calcite and anhydrite growth [e.g., Passchier and Trouw, 2005], and mineral precipitation occurred into a free fluid in an open vein. This is supported by the weak CPO of blocky calcite with the 'c' axis perpendicular to the vein margins: after nucleation along the vein margins, calcite crystals, which are trigonal and thus anisotropic, grow faster in direction of the 'c' axis. This process would result in a weak CPO due to growth competition [Nollet et al., 2005]. The intrusion of sheared shale into the veins is another indication that vein opening was sudden; disruption of foliation and calcite pore fillings within the intrusions suggest that the shale particles were mixed with fluids. The vein texture and their medium to high angle orientation to the foliation in the shale indicate that veins formed either as mode I fractures due to intrusion of pressurized shale material, or as hybrid shear - extensional [Ramsey and Chester, 2004] fractures. Following the Murrell-Griffith criterion of failure (Figure 3e), to form either extensional (mode I) or hybrid shear - extensional (modeI/modeII) fractures, it is necessary that the effective least principal stress is tensional: $\sigma_{3}^{\prime}=\left(\sigma_{3}-\mathrm{P}_{\mathrm{f}}\right)<0$. At about $2.7 \mathrm{~km}$ of depth, in the stress regime of the SAF, which is transitional between strike slip and reverse with $\sigma_{\mathrm{h}} \approx \sigma_{\mathrm{v}}$ as in the SAF, these conditions are satisfied when the fluid pressure is higher than lithostatic (Figure 3e).

[11] After sealing, the veins underwent further deformation, as suggested by twinning and stretching in calcite crystals. In elongated calcite, (1) the fine-scale alternation of light and dark luminescence rims and, (2) the 'c' axis preferentially oriented perpendicular to the vein margin (similar orientation as in the blocky grains), suggest incremental grain growth ("crack-seal", [Ramsay, 1980]), inheriting the orientation of the former blocky crystals (Figures $3 a-3 c$ ). The change in calcite luminescence, which is influenced by traces of $\mathrm{Fe}$ and $\mathrm{Mn}$, indicates a modification of fluid composition after the main fracturing episode.

[12] Following these observations, we propose that one of the possible mechanisms of rupture initiation in relatively "strong" rocks embedded within the damage zone of the SAF could be a transient increase of fluid pressure in isolated compartments where the circulation of fluids is limited by fault-parallel horizons consisting of insoluble minerals. Anomalies in the focal mechanisms of two M4 earthquakes in Parkfield area support a non double couple component, suggesting that some seismic ruptures might be initiated in presence of high fluid pressure and then propagate with a dominant shear component [Johnson and Mc Evilly, 1995]. Some of the "asperities" responsible for microearthquakes in the Parkfield segment of the SAF might thus be represented by compartments where the fluids might accumulate due to permeability reduction during compaction and pressure solution processes in clay-rich sedimentary inclusions or fault gouges [e.g., Sleep and Blanpied, 1992].

[13] Acknowledgments. We thank the HPHT INGV lab. for FE-SEM facilities (A. Cavallo, P. Scarlato). Grants: Padova University PhD scholarship (SM), CARIPARO project CD0504012134 (GDT), European Research Council Starting Grant Project 205175 (USEMS) (GDT and SAFS), INSU-C (JPG), Prin 2007BWMWM8 (RS). This material is based upon work supported by the US National Science Foundation NFS-Earthscope 0545472 (JH, GDT). We thank J. Richard, M.-L. Doan and Anne Marie Boullier for insightful discussions. The comments of D. Moore and J. Solum greatly improved the paper.

\section{References}

Bakun, W. H., et al. (2005), Implications for prediction and hazard assessment from the 2004 Parkfield earthquake, Nature, 437, 969-974, doi:10.1038/nature04067.

Boness, N., and M. D. Zoback (2006), A multi-scale study of the mechanisms controlling shear velocity anisotropy in the San Andreas Fault Observatory at Depth, Geophysics, 71(5), F131-F146, doi:10.1190/ 1.2231107.

Brune, J. N., T. L. Henyey, and R. F. Roy (1969), Heat flow, stress, and rate of slip along the San Andreas Fault, California, J. Geophys. Res., 74, 3821-3827, doi:10.1029/JB074i015p03821.

Chéry, J., M. D. Zoback, and S. Hickman (2004), A mechanical model of the San Andreas Fault and SAFOD pilot hole stress measurements, Geophys. Res. Lett., 31, L15S13, doi:10.1029/2004GL019521.

Dreger, D., R. M. Nadeau, and A. Chung (2007), Repeating earthquake finite source models: Strong asperities revealed on the San Andreas Fault, Geophys. Res. Lett., 34, L23302, doi:10.1029/2007GL031353.

Ferrill, D. D., A. P. Morris, M. A. Evans, M. Burkhard, R. H. Groshong Jr., and C. M. Onasch (2004), Calcite twin morphology: A low temperature deformation geothermometer, J. Struct. Geol., 26, 1521-1529, doi:10.1016/j.jsg.2003.11.028.

Gratier, J. P., J. Richard, S. Mittempergher, F. Renard, M. Doan, G. Di Toro, J. Hadizadeh, and A. M. Boullier Bertrand (2009), Pressure solution as a mechanism of creep and sealing in active faults: Evidence from the SAFOD samples, Eos Trans. $A G U$, 90(52), Fall Meet. Suppl., Abstract T21B-1800.

Hickman, S. H., and M. D. Zoback (2004), Stress orientation and magnitudes in the SAFOD pilot hole, Geophys. Res. Lett., 31, L15S12, doi:10.1029/2004GL020043.

Imanishi, K., and W. L. Ellsworth (2006), Source scaling relationships of microearthquakes at Parkfield, CA, determined using the SAFOD pilot hole seismic array, in Earthquakes: Radiated Energy and the Physics of Earthquake Faulting, Geophys. Monogr. Ser., vol. 170, edited by R. Abercrombie et al., pp. 81-90, AGU, Washington, D. C.

Johnson, P. A., and T. V. Mc Evilly (1995), Parkfield seismicity: Fluid driven?, J. Geophys. Res., 100, 12,937-12,950, doi:10.1029/95JB00474.

Moore, D. E., and M. J. Rymer (2007), Talc-bearing serpentinite and the creeping section of the San Andreas Fault, Nature, 448, 795-797, doi:10.1038/nature06064.

Nadeau, R. M., and L. R. Johnson (1998), Seismological studies at Parkfield VI: Moment release rates and estimates of source parameters for small repeating earthquakes, Bull. Seismol. Soc. Am., 88, 790-814.

Nadeau, R. M., A. Michelini, R. A. Uhrhammer, D. Dolenc, and T. V. McEvilly (2004), Detailed kinematics, structure and recurrence of micro-seismicity in the SAFOD target region, Geophys. Res. Lett., 31, L12S08, doi:10.1029/2003GL019409.

Nollet, S., J. L. Urai, P. D. Bons, and C. Hilgers (2005), Numerical simulations of polycrystal growth in veins, J. Struct. Geol., 27, 217-230, doi:10.1016/j.jsg.2004.10.003.

Passchier, C. W., and R. A. J. Trouw (2005), Microtectonics, 366 pp., Springer, Berlin.

Ramsay, J. G. (1980), The crack-seal mechanism of rock deformation, Nature, 284, 135-139, doi:10.1038/284135a0.

Ramsey, J. M., and F. M. Chester (2004), Hybrid fracture and the transition from extension fracture to shear fracture, Nature, 428, 63-66, doi:10.1038/nature02333.

Rice, J. R. (1992), Fault stress states, pore pressure distribution, and the weakness of the San Andreas Fault, in Fault Mechanics and Transport Properties of Rocks, edited by B. Evans and T. F. Wong, pp. 475503, Academic, San Diego, Calif., doi:10.1016/S0074-6142(08)62835-1.

Schleicher, A. M., S. N. Tourscher, B. A. van der Pluijm, and L. N. Warr (2009), Constraints on mineralization, fluid-rock interaction, and mass transfer during faulting at $2-3 \mathrm{~km}$ depth from the SAFOD drill hole, J. Geophys. Res., 114, B04202, doi:10.1029/2008JB006092. 
Sleep, N. H., and M. L. Blanpied (1992), Creep, compaction and the weak rheology of major faults, Nature, 359, 687-692, doi:10.1038/359687a0.

Solum, J. G., S. H. Hickman, D. A. Lockner, D. E. Moore, B. A. van der Pluijm, A. Schleicher, and J. P. Evans (2006), Mineralogical characterization of protolith and fault rocks from the SAFOD main hole, Geophys. Res. Lett., 33, L21314, doi:10.1029/2006GL027285.

Titus, S. J., C. DeMets, and B. Tikoff (2006), Thirty-five-year creep rates for the creeping segment of the San Andreas Fault and the effects of the 2004 Parkfield earthquake: Constraints from alignment arrays, continuous Global Positioning System, and creepmeters, Bull. Seismol. Soc. Am., 96, S250-S268, doi:10.1785/0120050811.

Wiersberg, T., and J. Erzinger (2008), Origin and spatial distribution of gas at seismogenic depths of the San Andreas Fault from drill-mud gas analysis, Appl. Geochem., 23, 1675-1690, doi:10.1016/j.apgeochem.2008.01.012.
Zoback, M., S. Hickman, and W. Ellsworth (2010), Scientific drilling into the San Andreas Fault Zone, Eos Trans. AGU, 91(22), doi:10.1029/ $2010 \mathrm{EO} 220001$.

G. Di Toro, S. Mittempergher, and R. Spiess, Dipartimento di Geoscienze, Università di Padova, Via G. Gradenigo 6, I-35131 Padova, Italy. (silvia.mittempergher@unipd.it)

J. P. Gratier, LGIT, Université Joseph Fourier - Grenoble I, BP 53, F-38041 Grenoble CEDEX 9, France.

J. Hadizadeh, Department of Geography and Geosciences, University of Louisville, 212 Lutz Hall, Louisville, KY 40292, USA.

S. A. F. Smith, Istituto Nazionale di Geofisica e Vulcanologia, Via di Vigna Murata, 605, I-00143 Roma, Italy. 